\title{
Human monocyte interactions with non-enzymatically glycated collagen
}

\author{
M.Z. Gilcrease and R.L.Hoover \\ Department of Pathology, Vanderbilt University, Nashville, Tennessee, USA
}

\begin{abstract}
Summary. We have previously shown that receptors for advanced glycation end products are expressed on activated human monocytes. We now report that activated human monocytes exhibit increased adhesion to non-enzymatically glycated collagen substrates $(+32 \% \pm 1, p<0.001)$, and the increased adhesion can be competitively inhibited with non-enzymatically glycated albumin. Non-activated monocytes, which do not express receptors for advanced glycation end products, exhibit decreased adhesion $(-16 \% \pm 1$, $p<0.001$ ). Similar results were observed with substrates of fibronectin and endothelial cell matrix proteins. As the presence of glycation adducts on collagen interferes with the normal binding of monocytes/macrophages, one possible
\end{abstract}

role for advanced glycation adduct receptors on activated monocytes is to counterbalance such decreased adherence. Overcompensation for long periods of time may lead to pathological changes. Additionally, such receptors may play a role in monocyte-mediated remodelling of glycated matrix proteins, as we have observed increased degradation of nonenzymatically glycated collagen substrates by activated human monocytes at $2 \mathrm{~h}(+52 \% \pm 11, p=0.01), 3 \mathrm{~h}(+49 \%$ $\pm 10, p=0.01)$, and $4 \mathrm{~h}(+36 \% \pm 6, p<0.01)$ after adding activated monocytes to ${ }^{125}$ I-labelled substrates.

Key words: Monocyte, glucose, endotoxin, adhesion, nonenzymatic glycation, collagen.
There is growing evidence to show that the non-enzymatic glycation of proteins may play an important role in the pathogenesis of diabetic vascular disease [1-9]. Receptors for advanced glycation end products (AGE-receptors) were initially identified on murine macrophages $[10,11]$. They have since been demonstrated on cultured human monocytes [12], and we have identified them on freshly isolated human monocytes following endotoxin activation [13]. Purification from membranes of the macrophage cell line RAW 264.7 has revealed that the receptor has an 83,000-dalton subunit involved in ligand binding and a 36,000-dalton subunit of unknown function [14]. It is thought that the receptor mediates macrophage recognition of non-enzymatic glycation adducts formed on interstitial matrix proteins.

We have previously shown that activated human monocytes exhibit a greater than six-fold increase in adherence to an AGE-albumin substrate compared to control albumin [13]. This increase was competitively inhibited when adherence to the glycated substrate was measured in the presence of soluble AGE-BSA, indicating that recognition of AGE adducts on the albumin substrate was specific [13]. Basement membrane proteins and aortic collagen have been shown in vivo to accumulate large amounts of AGE adducts in diabetic rats $[15,16]$. If receptor-mediated adherence of activated monocytes to non-enzymatically glycated proteins occurs within the walls of blood vessels, it may contribute to intimal monocyte accumulation and the development of atherosclerosis.

The present study examines whether activated human monocytes/macrophages exhibit altered adherence to non-enzymatically glycated collagen substrates. As AGEreceptors on murine macrophages have been shown to mediate the uptake and degradation of a variety of soluble non-enzymatically glycated proteins [10], we also examined whether activated human monocytes would exhibit increased degradation of AGE-collagen substrates.

\section{Materials and methods}

\section{Monocyte isolation}

Whole human blood was collected into EDTA-vacutainer tubes and layered over Histopaque-1077 (Sigma Chemical Co, St. Louis, Mo., USA). Following centrifugation at $700 \times g$ for $30 \mathrm{~min}$, the mononuclear layer was collected, washed in phosphate-buffered saline (PBS) with $0.1 \%$ bovine serum albumin (BSA), and suspended in 


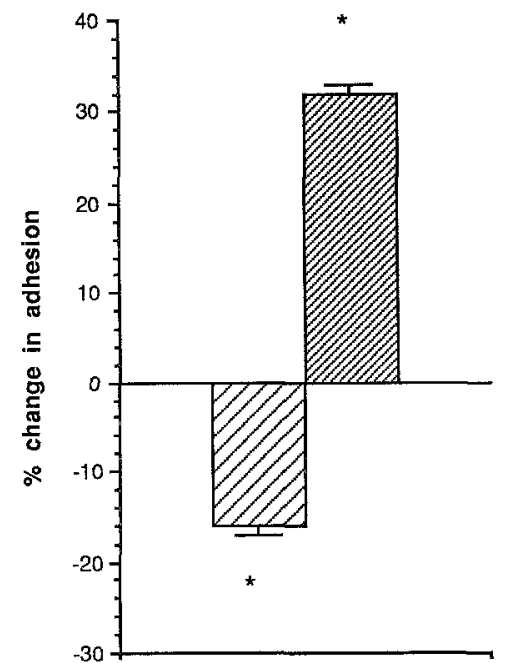

Fig. 1. Adhesion of freshly-isolated ( 7$)$ or endotoxin-activated (ש্) human monocytes to non-enzymatically glycated collagen substrates. Data is expressed as percent change in adhesion compared to adhesion on normal collagen substrates. Error bars represent SEM. $n=3, * p<0.001$

Roswell Park Memorial Institute (RPMI) $+10 \%$ Supplemented Calf Serum (SCS, Gibco Laboratories, Grand Island, N. Y., USA). Percoll (Sigma) gradients were prepared following the addition of one part $10 \times \mathrm{PBS}$ to nine parts Percoll to bring Percoll to isotonicity. $1 \mathrm{ml}$ of SCS and $14.5 \mathrm{ml}$ of PBS were added to $22 \mathrm{ml}$ of isotonic Percoll, and centrifugation was performed at $34,000 \times \mathrm{g}$ for $30 \mathrm{~min}$ at $5^{\circ} \mathrm{C} .5 \mathrm{ml}$ of the mononuclear cell suspension $\left(1 \times 10^{6} \mathrm{cells} / \mathrm{ml}\right)$ was layered over each Percoll gradient and centrifuged at $1300 \times \mathrm{g}$ for $20 \mathrm{~min}$ at $5^{\circ} \mathrm{C}$. The top major band was then collected and washed twice in PBS with $0.1 \%$ BSA to remove platelets. Wright's stain revealed a monocyte purity of $\geq 95 \%$. Some monocytes were then activated by incubating them with lipopolysaccharide B (Escherichia coli 0127: B8, Difco Laboratories, Detroit, Mich., USA) at a concentration of $10 \mu \mathrm{g} / \mathrm{ml}$ at $37^{\circ} \mathrm{C}$ for $1 \mathrm{~h}$. The monocytes used in adherence assays were labelled at $4{ }^{\circ} \mathrm{C}$ for $1 \mathrm{~h}$ with ${ }^{51} \mathrm{Cr}(100 \mu \mathrm{Ci} / \mathrm{ml}$ of cell suspension, New England Nuclear, Boston, Mass., USA), rinsed, and resuspended at a concentration of $1 \times 10^{6} \mathrm{cells} / \mathrm{ml}$.

\section{Preparation of non-enzymatically glycated proteins}

Purified collagen (Vitrogen 100, Collagen Corporation, Palo Alto, Calif., USA) and fibronectin (Sigma) were non-enzymatically glycated by incubation in Hanks' balanced salt solution (HBSS) with sodium bicarbonate $(\mathrm{pH} 8.0)$ at $37^{\circ} \mathrm{C}$ for 3 weeks in the presence of $200 \mathrm{mmol} / \mathrm{l}$ glucose. Similar treatment has been shown to produce large amounts of AGE-adducts $[9,10]$. Controls were incubated for 3 weeks without glucose. Suspensions were subsequently dialysed overnight to remove free glucose, and aliquots were used for protein determination using the BCA Protein Assay Reagent (Pierce Chemical Co., Rockford, Ill., USA).

Endothelial cell matrices were prepared by first isolating endothelial cells from bovine pulmonary arteries. The arteries were obtained from a local slaughterhouse and transported to the laboratory in Hanks' balanced salt solution with $10 \mathrm{mmol} / \mathrm{l}$ HEPES, pH 7.4 (buffered HBSS) with antibiotics. Arteries were flushed with buffered HBSS, sliced longitudinally to expose the endothelial surface, incubated in $0.1 \%$ collagenase for $20 \mathrm{~min}$ at $37^{\circ} \mathrm{C}$, and gently scraped. Following centrifugation at $3000 \times g$ for $5 \mathrm{~min}$, the cells were suspended in Dulbecco's Modified Eagle's Medium (DME) with $5 \%$ SCS and $5 \%$ NuSerum (NS, Collaborative Research, Bedford, Mass., USA) and antibiotics. Cells were plated in 24-well tissue culture plates, grown to confluence, and identified as endothelial by their cobblestone morphology [17], positive immunofluorescence staining for factor VIII [18], and the binding and uptake of fluorescently-labelled acetylated LDL [19]. Monolayers were then lysed with $0.5 \mathrm{mmol} / 1 \mathrm{NH}_{4} \mathrm{OH}$, and the wells were washed extensively in buffered HBSS. Phase-contrast microscopy revealed that all cells were lysed and completely washed away. Matrix-coated wells were then incubated in HBSS with sodium bicarbonate ( $\mathrm{pH} 8.0$ ) for 3 weeks at $37^{\circ} \mathrm{C}$ in the presence of $200 \mathrm{mmol} / \mathrm{l}$ glucose, while control matrices were incubated for 3 weeks without glucose.

\section{Monocyte adherence assays}

Solutions of collagen $(8.5 \mu \mathrm{g} /$ well) and non-enzymatically glycated collagen $(8.5 \mu \mathrm{g} / \mathrm{well})$ were added to tissue-culture wells and allowed to dry at $37^{\circ} \mathrm{C}$. Solutions of fibronectin and non-enzymatically glycated fibronectin $(0.6 \mu \mathrm{g} /$ well $)$ were similarly allowed to dry at $37^{\circ} \mathrm{C}$. Endothelial cell matrices were also prepared as described above. $200 \mu \mathrm{l}$ of a solution of freshly isolated or activated ${ }^{51} \mathrm{Cr}$-labelled monocytes $\left(1 \times 10^{6}\right.$ cells $/ \mathrm{ml}$ of buffered HBSS $)$ were then added to each well and allowed to incubate at $37^{\circ} \mathrm{C}$ for $5 \mathrm{~min}$, as the greatest differences between adhesion to non-enzymatically glycated substrates and to controls were observed at this time point. Some assays involved pre-incubation of labelled monocytes with BSA $(5 \mathrm{mg} / \mathrm{ml})$ or non-enzymatically glycated BSA for $30 \mathrm{~min}$ at $4{ }^{\circ} \mathrm{C}$, followed by adherence in the presence of BSA or glycated BSA. Wells were subsequently washed with buffered HBSS, and adherent cells were lysed overnight in $0.5 \mathrm{mmol} / \mathrm{l} \mathrm{NH} \mathrm{H}_{4} \mathrm{OH}$. Percent adherence (calculated as the number of counts remaining after washing divided by total counts added at the beginning of the assay) was quantitated by scintillation counting.

\section{Collagen degradation studies}

Normal collagen and AGE-collagen were radioiodinated with carrier-free ${ }^{125} \mathrm{I}$ (New England Nuclear) by the IODO-GEN method of Fraker and Speck [20] and recovered by trichloroacetic acid (TCA) precipitation. Specific activities for ${ }^{125} \mathrm{I}$-collagen and ${ }^{125} \mathrm{I}$-glycated collagen were $4.88 \times 10^{4} \mathrm{cpm} / \mu \mathrm{g}$ and $4.56 \times 10^{4} \mathrm{cpm} / \mu \mathrm{g}$, respectively. Solutions of labelled collagen and AGE-collagen were then added to tissue-culture wells $(500 \mathrm{ng} / \mathrm{well})$ and allowed to dry at $37^{\circ} \mathrm{C} .200 \mu \mathrm{l}$ of a suspension of activated monocytes $\left(1 \times 10^{6} \mathrm{cells} / \mathrm{ml}\right.$ of buffered HBSS) was added to triplicate wells containing labelled collagen and AGE-collagen substrates and incubated at $37^{\circ} \mathrm{C}$ for periods of between 1 and $4 \mathrm{~h}$. To determine the amount of matrix protein degraded, the media were collected, the matrices were washed, and the media and washings were pooled. TCA precipitation was performed using $20 \%$ TCA, and the amount of non-precipitable radioactivity in the supernatants was subsequently quantitated by scintillation counting.

\section{Statistical analysis}

The Student's unpaired $t$-test was used to determine whether values obtained from the monocyte adherence assays and collagen degradation studies were significantly different from control values.

\section{Results}

When freshly isolated human monocytes were allowed to adhere to substrates of AGE-collagen or normal collagen, a small but significant decrease $(-16 \% \pm 1, p<0.001)$ in adhesion to the glycated substrate was observed compared to the normal collagen substrate (Fig. 1). (As monocytes were isolated from different donors on different days, the absolute adhesion of freshly isolated monocytes 


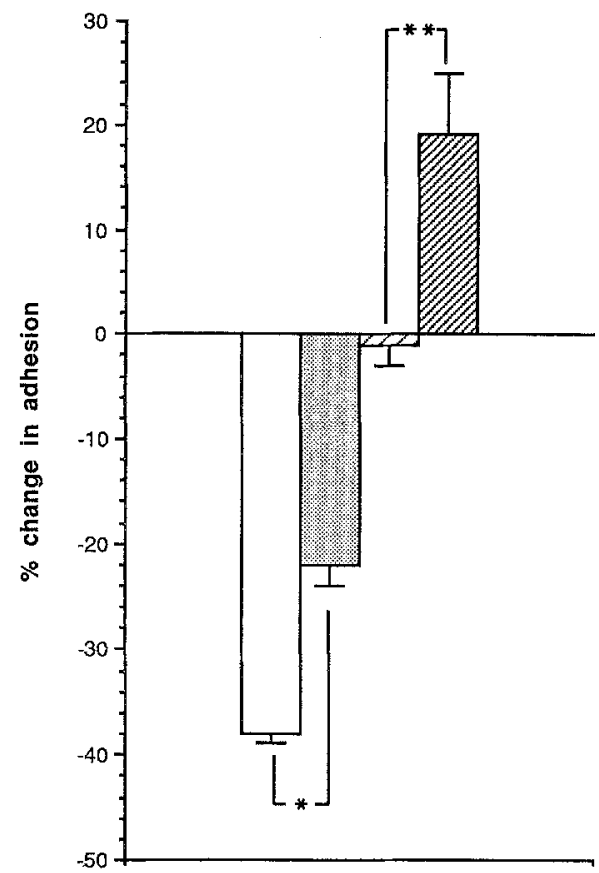

Fig. 2. Adhesion of freshly-isolated $(\square)$ or endotoxin-activated (1) human monocytes to substrates of non-enzymatically glycated fibronectin $(n=4)$, and adhesion of freshly-isolated ( $\square)$ or endotoxin-activated (ש) human monocytes to substrates of non-enzymatically glycated matrix protein secreted by endothelial cells $(n=3)$. Data is expressed as percent change in adhesion compared to adhesion on normal substrates. Error bars represent SEM. $* p<0.001, * * p<0.03$

to normal collagen substrates ranged from $13 \%$ to $45 \%$. Therefore, all adhesion data are expressed as percent of control adhesion.) Such a decrease would be expected from the addition of AGE-adducts on lysine residues of collagen sequences recognized by monocyte receptors. However, when endotoxin-activated monocytes (known to express AGE-receptors) [13] were allowed to adhere to substrates of AGE-collagen or normal collagen, an increase in adhesion $(+32 \% \pm 1, p<0.001)$ was observed. This increase is consistent with receptor-mediated recognition of $\mathrm{AGE}$-adducts.

Assays performed with substrates of AGE-fibronectin and AGE-matrix protein secreted by large vessel endothelial cells (AGE-BPA) showed similar results (Fig.2). The adherence of non-activated monocytes to AGE-fibronectin was much less than adhesion to control fibronectin $(-38 \% \pm 1, p<0.001)$, whereas adhesion to AGEBPA was not significantly different from adhesion to the control substrate. However, the amount of decrease in adhesion to AGE-fibronectin compared to control fibronectin was less with activated monocytes than with nonactivated monocytes $(-22 \% \pm 2, p<0.001)$. Similarly, adhesion to AGE-BPA compared to control substrates was greater with activated monocytes than with non-activated monocytes $(+19 \% \pm 6, p<0.03)$.

To determine whether the increased adhesion of activated monocytes to $A G E-c o l l a g e n$ was due specifically to the presence of AGE-adducts on the substrate, competition experiments were performed using soluble ligands with AGE-adducts. Figure 3 shows that the increased adherence of activated monocytes to the non-enzymatically glycated collagen substrate could be competitively inhibited by AGE-BSA.

The degradation of AGE-collagen and normal collagen by activated human monocytes was subsequently quantitated using ${ }^{125} \mathrm{I}$-labelled substrates. Figure 4 shows that degradation of the non-enzymatically glycated collagen substrate was significantly higher than the normal collagen substrate at $2 \mathrm{~h}(+52 \% \pm 12, p=0.01), 3 \mathrm{~h}$ $(+49 \% \pm 10, p=0.01)$, and $4 \mathrm{~h}(+36 \% \pm 6, p<0.01)$ after the addition of activated human monocytes to the substrates.

\section{Discussion}

We have shown previously that freshly isolated human monocytes do not express significant numbers of AGEreceptors. In this report, freshly isolated human monocytes have been shown to exhibit decreased adherence to AGE-collagen substrates compared to control substrates. It appears, therefore, that the presence of AGE-adducts on sequences involved in monocyte adherence to collagen interferes with the normal recognition of collagen.

In contrast, AGE-receptors have been demonstrated previously on murine macrophages $[10,11]$. They have also been shown to be present on human monocytes following 2 days in culture [12], and we have shown that receptors can be expressed on freshly isolated human monocytes following endotoxin-activation [13]. The adherence of endotoxin-activated human monocytes to AGE-collagen substrates is increased compared to control collagen

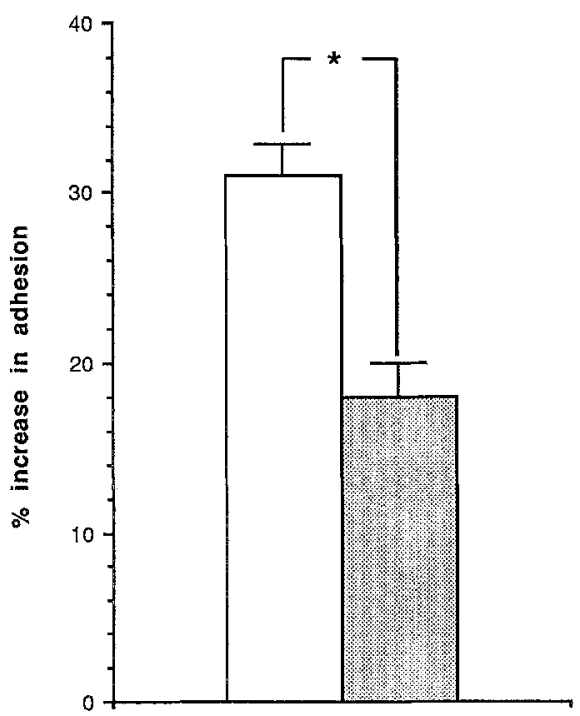

Fig.3. Adhesion of endotoxin-activated human monocytes to nonenzymatically glycated collagen substrates in the presence of bovine serum albumin (BSA, $5 \mathrm{mg} / \mathrm{ml}$ ) following pre-incubation of the monocytes for 30 min with BSA $(\square)$, or in the presence of non-enzymatically glycated BSA (AGE-BSA, $5 \mathrm{mg} / \mathrm{ml}$ ) following pre-incubation of the monocytes for $30 \mathrm{~min}$ with AGE-BSA ( Data is expressed as percent increase in adhesion compared to adhesion on normal collagen substrates. Error bars represent SEM. $n=3$, $* p<0.02$ 


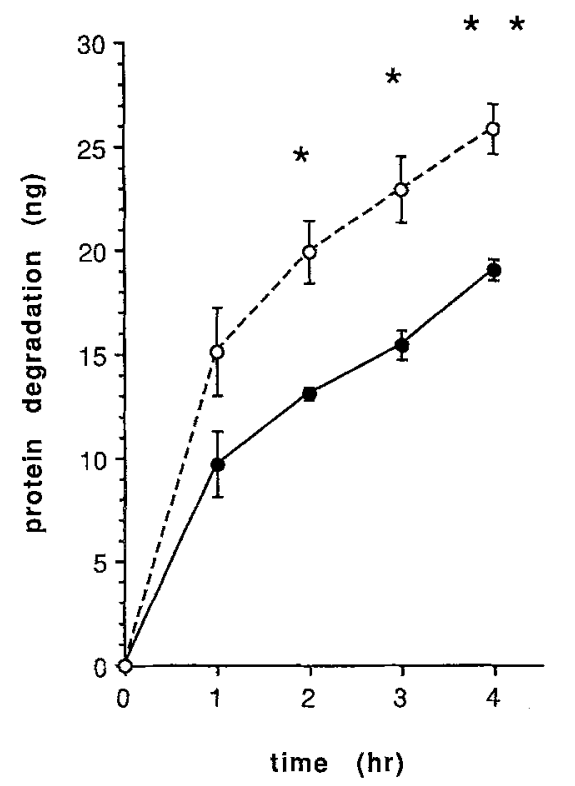

Fig.4. Degradation of ${ }^{125}$ I-labelled normal collagen substrates ( $)$ or non-enzymatically glycated collagen substrates $(O)$ by endotoxin-activated human monocytes. Data represents non-precipitable radioactivity following trichloroacetic acid precipitation of the incubation media. $n=3,{ }^{*} p=0.01$, ${ }^{* *} p<0.01$

substrates. Specific recognition of AGE-adducts is involved in such adherence, as significant inhibition is found in the presence of soluble AGE-BSA.

We believe these findings suggest a possible physiological role for the AGE-receptor. The presence of AGE-adducts on long-lived interstitial proteins increases both in diabetic subjects [3-5] and in normal individuals during aging $[7,10]$, and cells which do not express AGE-receptors would be expected to show decreased adherence to such matrix proteins if non-enzymatic glycation adducts were formed on sequences important in cell-to-matrix adherence. The presence of AGE-receptors on the cell surface, however, would allow cells to compensate for such decreased adherence by specifically recognizing AGE adducts, thereby restoring cell-to-matrix adherence.

The expression of AGE-receptors on non-diabetic activated monocytes may have relevance for the normal aging process, as long-lived interstitial proteins undergo increased non-enzymatic glycation during normal aging. In diabetes, as even greater levels of AGE-adducts accumulate on long-lived proteins, one might expect AGEreceptors to become upregulated. This, in fact, occurs in diabetic rats. Alloxan-induced diabetic rats exhibit a twoto three-fold increase in the number of AGE-receptors per macrophage [21].

If receptor-mediated recognition of AGE-adducts becomes excessive, increased adherence and accumulation of activated monocytes may occur within the vascular interstitium. Increased intimal accumulation of monocytes is known to be an early stage in the pathogenesis of atherosclerosis [22], and the incidence of atherosclerosis is greatly increased in diabetes [23]. It is unclear whether the $30-40 \%$ increases in adherence to AGE-protein substrates in vitro reported here would be significant enough to promote disease in vivo. As atherosclerosis is a very slow process requiring many years to develop, it appears reasonable that small increases in adherence over long periods of time could contribute to fatty streak formation and subsequent atherosclerosis. Notwithstanding, the AGE-receptor in vivo may act primarily to prevent disease by counterbalancing what would otherwise be impaired cell-to-matrix adherence.

Our finding that the AGE-receptor appears to mediate increased degradation of AGE-collagen, on the other hand, may have relevance for tissue remodelling in diabetes. Additionally, as levels of AGE-adducts on interstitial proteins increase with age in normal individuals, increased degradation of AGE-collagen by tissue macrophages may play a normal role in the aging process $[7,10]$.

Acknowledgements. We wish to thank Ms. R. L. Jones for her excellent technical assistance. This work was supported by NIH grant HL-36526 to RLH.

\section{References}

1. Cerami A, Vlassara H, Brownlee $M$ (1985) Protein glycosylation and the pathogenesis of atherosclerosis. Metab Clin Exp 12 [Suppl 1]: 37-42

2. Winterhalter KH (1985) Nonenzymatic glycosylation of proteins. Prog Clin Biol Res 195: 109-129

3. Vlassara H, Brownlee M, Cerami A (1986) Nonenzymatic glycosylation: role in the pathogenesis of diabetic complications. Clin Chem 32 [Suppl 10]: B37-41

4. Brownlee M, Cerami A, Vlassara H (1988) Advanced products of nonenzymatic glycosylation and the pathogenesis of diabetic vascular disease. Diabetes Metab Rev 4: 437-451

5. Brownlee M, Cerami A, Vlassara H (1988) Advanced glycosylation end products in tissue and the biochemical basis of diabetic complications. N Engl J Med 318: 1315-1321

6. Reynolds TM (1965) Chemistry of nonenzymatic browning. Adv Food Res 14: 167-283

7. Monnier VM, Cerami A (1981) Nonenzymatic browning in vivo: possible process for aging for long-lived proteins. Science 211 : $491-493$

8. Monnier VM, Cerami A (1982) Nonenzymatic glycosylation and browning of proteins in diabetes. Clin Endocrinol Metab 11: $431-452$

9. Sakurai T, Takahashi H, Tsuchiya S (1984) New flourescence of nonenzymatically glycosylated human serum albumin. FEBS Lett 176: 27-31

10. Vlassara H, Brownlee M, Cerami A (1985) High-affinity receptor-mediated uptake and degradation of glucose-modified proteins: a potential mechanism for removal of senescent macromolecules. Proc Natl Acad Sci USA 82: 5588-5592

11. Vlassara H, Brownlee M, Cerami A (1986) Novel macrophage receptor for glucose-modified proteins is distinct from previously-described scavenger receptors. J Exp Med 164: 13011309

12. Vlassara H, Moldawer L, Chan B (1989) Macrophage/monocyte receptor for nonenzymatically glycosylated protein is upregulated by cachectin/tumor necrosis factor. J Clin Invest 84: 18131820

13. Gilcrease MZ, Hoover RL (1990) Activated human monocytes exhibit receptor-mediated adhesion to a non-enzymatically glycosylated protein substrate. Diabetologia 33: 329-333

14. Radoff S, Vlassara H, Cerami A (1988) Characterization of a solubilized cell surface binding protein on macrophages specific for proteins modified nonenzymatically by advanced glycosylated end products. Arch Biochem Biophys 263: 418-423 
15. Nicholls K, Mandel TE (1989) Advanced glycosylation end products in experimental murine diabetic nephropathy: effect of islet isografting and of aminoguanidine. Lab Invest 60: 486-491

16. Brownlee M, Vlassara H, Kooney A, Ulrich P, Cerami A (1986) Aminoguanidine prevents diabetes-induced arterial wall protein cross-linking. Science 232: 1629-1632

17. Haudenschild CC (1984) Morphology of vascular endothelial cells in culture. In: Jaffe EA (ed) Biology of endothelial cells. Martinus Nijhoff, Boston, pp129-140

18. Johnson AR (1980) Human pulmonary endothelial cells in culture. J Clin Invest 65: 841-850

19. Stein O, Stein Y (1980) Bovine aortic cells display macrophagelike properties toward acetylated (1-125)-labeled low density lipoprotein. Biochim Biophys Acta 620: 631-635

20. Fraker PJ, Speck JC (1978) Protein and cell membrane iodinations with a sparingly soluble chloramide, 1,3,4,6-tetrachloro3a,6a-diphenylglycoluril. Biochem Biophys Res Comm 80: 849857
21. Vlassara H, Brownlee M, Cerami A (1988) Specific macrophage receptor activity for advance glycosylation end products inversely correlates with insulin levels in vivo. Diabetes $37: 456-461$

22. Harlan JM (1985) Leukocyte-endothelial interactions. Blood 65: $513-525$

23. Banga JD, Sixma JJ (1986) Diabetes mellitus, vascular disease and thrombosis. Clin Haematol 15: 465-491

Received: 10 May 1991

and in revised form: 9 October 1991

Dr. R.L.Hoover

Department of Pathology

School of Medicine

Vanderbilt University

Nashville, TN 37232

USA 